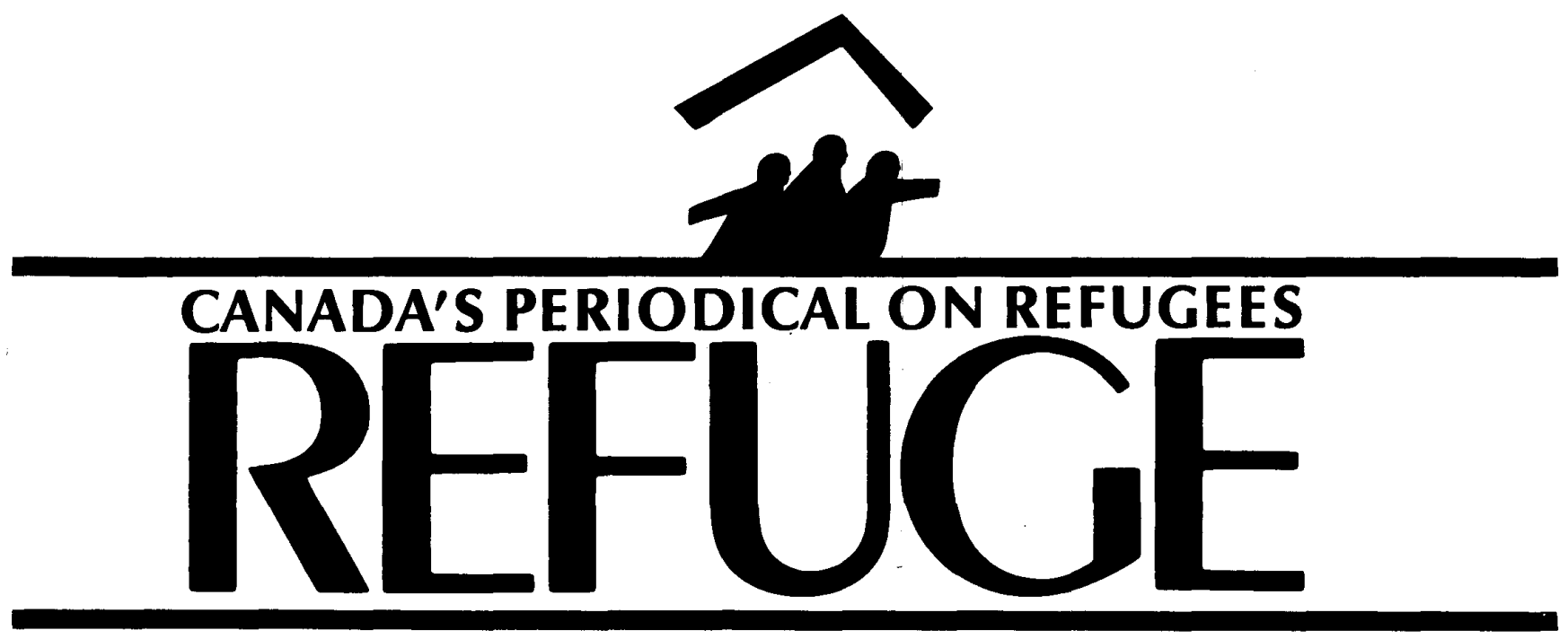

Vol. 9, No. 4

May 1990

\title{
Convention and Humanitarian Refugees
}

This issue focuses on the two fundamental aspects of Canadian refugee policy - the refugee determination system dealing with claimants who arrive in Canada and claim to be Convention refugees, and the designated classes and special measures focused on humanitarian refugees whom we select abroad under relaxed immigration criteria.

In the interview with Gordon Fairweather, Chairman of the Immigration and Refugee Board, and in the one with Lorne Waldman, a prominent refugee lawyer in Toronto, we have two very contrasting views of the current refugee determination system. From one perspective, the system is somewhat short of perfection, but in the process of evolving in that direction. From the critical perspective, the system is about to implode on itself.

In the pieces dealing with humanitarian refugees, the central concern is the self-exiled class, those who fled communist regimes in Eastern Europe (excepting Yugoslavia) and were granted refugee status on humanitarian grounds. With glasnost in the
Soviet Union and the sudden and radical transformation of authoritarian communist regimes in that area into societies in transition to democra$c y$, the application of the self-exiled category as a rubric for receiving refugees from Eastern Europe becomes suspect and brings the whole meaning and rationale for special refugee measures into disrepute.

The articles deal with those issues. This editorial, however, is not concerned with the crisis within either the regime dealing with Convention refugees or the one dealing with humanitarian refugees but the emerging one between Convention and humanitarian refugees.

In the late 70 s Canada received 200 to 400 spontaneous arrivals claiming refugee status. Between 1982 and 1986, RSAC, the Refugee Status Advisory Committee then vested with the prime responsibility of dealing with Convention refugee claimants, began receiving 2,500 to 4,000 claims per year, a tenfold increase. As we enter the 90 s, the Immigration and Refugee Board, whether efficient or inefficient, whether approaching ideal standards of fairness or failing any fairness test, will be receiving between 20,000 and, some estimate, up to 40,000 refugee claims per year, another tenfold

\section{IN THIS ISSUE:}

An Interview with Gordon Fairweather by Alex Zisman

page 3

Lorne Waldman Speaks by Alex Zisman

page 10

New Guidelines on Discretionary Powers

page 15

East European Refugee Symposium

page 18

The Self-Exiled Class by David Matas

page 22 
increase. For the first time, the Convention refugee program will surpass the humanitarian refugee program.

In a discussion paper specified for official use only in the early 80 s, Raphael Girard, who emerged later as the civil servant charged with drafting Bill C-55 (not to mention C-84), the legislation which is the basis for currently dealing with Convention refugee claims, wrote, "it is not desirable to have a resettlement program straddling two main themes, active off-shore selection and the use of asylum as a pro-active program." Girard argued against tolerating a spontaneous inflow of refugees in favour of off-shore selection program. The for-

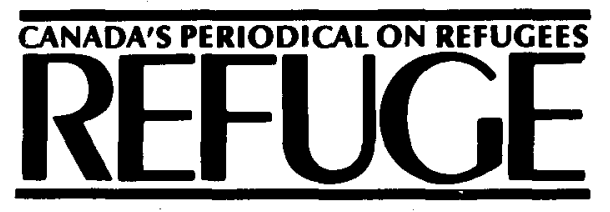

Centre for Refuge Studies, Yodk University, Suite 234, Administrative Studies Building. 4700 Keele Street, North York, Ontario, Canada M3J 1 P3. Telephone: (416) 736-5663. Fax: (416) 736-5687. Electronic Mail Via Bitnet Address: REFUGE@YORKVM1. mer was subject to abuse, lack of control and was prone to become involved in legal entanglements. The latter was subject to management and planning, was sensitive to the Canadian public's political preferences, could be aligned with our foreign policy priorities and would avoid the cumbersome and tremendously difficult problem of removals.

Some fear that the increasing number of spontaneous arrivals claiming Convention refugee status will result in the government implementing the "safe third country" provision in the new legislation which Raphael Girard had included precisely to deter and limit large numbers of legitimate refugee claimants which have emerged as anticipated. Claimants who could have made a claim in a country they transited on route to Canada would be sent back to that country.
But there is another fear. The danger may not be that the current Convention refugee determination process is in danger by new government initiatives to undermine it, but that the Canadian program which allows a flexible response towards refugees who may not be able to prove as individuals that they are subject to a well-founded fear of persecution may be sacrificed to pay the increasing costs of handling Convention refugee claims within Canada. We may be on the verge of an impending attack and an attempt to dismantle the humanitarian refugee program.

The discussion on the current refugee determination process and the problems with the self-exiled class should be read with this as a possibility.

\section{Immigration and Refugee Board Status of Claims}

\section{Editor: \\ Howard Adelman \\ Executive Editor: \\ Alex Zisman \\ Circulation Manager: \\ Helen Gross \\ Assistant to the Circulation Manager: Ching Man (C.M.) Wong}

Refuge is dedicated to the encouragement of assistance to refugees by providing a forum for sharing information and opinion on Canadian and international issues pertaining to refugees. It is published four times a year by the Centre for Refugee Studies. It is a non-profit, independant periodical supported by private donations and by subscriptions. It is a forum for discussion, and the views expressed do not necessarily reflect those of its funders or staff.

All material in Refuge may be reproduced without permmiston unless copyrighted or otherwise indicated. Credit should be given to the author or source, if named.

Subscription rates for one year are $\$ 20.00$ in Canada and US, $\$ 25.00$ overseas. Please enclose payment with your onder.

Logo Design:

Dreadnought Co-operative Inc., Toronto

Layout:

Pages Plus, 131 Atkinson, York University

Second Class Mail Registration No. 5512 ISSN 0229-5113

\section{January 1 - March 31, 1990}

\begin{tabular}{lrrrrrr} 
Initial Hearing Stage & Atlantic & Quebec & Ontario & Prairies & \multicolumn{2}{c}{ B.C. National } \\
& 212 & 1883 & 3308 & 114 & 470 & 5987 \\
Claims initiated & 6 & 76 & $(24)^{*}$ & 9 & 41 & 108 \\
Hearings adjourned/postponed & 5 & 14 & 29 & 4 & 7 & 59 \\
Claims withdrawn/abandoned & 201 & 1793 & 3303 & 101 & 422 & 5820 \\
Decisions rendered & & & & &
\end{tabular}

- More claims were concluded then initiated.

Of these decisions

Claims rejected:

Eligibility

Credible basis

Claims to full hearing

0
21
180

2
49
1742

7
91
3205

0
12

0

89

$\begin{array}{rr}1 & 10 \\ 10 & 183 \\ 411 & 5627\end{array}$

Full Hearing Stage

Atlantic

Quebec

Claims heard to compleation

Decisions rendered

$\begin{array}{rrrrrr}72 & 1228 & 1600 & 107 & 266 & 3273 \\ 23 & 906 & 1355 & 90 & 170 & 2544\end{array}$

Decisions pending at

December 31, 1989

Decisions pending at

March 31, 1990

Claims withdrawn/abandoned

51
100
0
7
16

519

390

42

97

1099

Of these decisions

Claims rejected

Claims upheld

841
12

635

23

59

59
2

193

1828

195
711

189
1166

11
79

60

110

462 